\title{
Association between Physical Activity and Comorbidities in Spanish People with Asthma-COPD Overlap
}

\author{
Sheila Sánchez Castillo ${ }^{1, *(\mathbb{D})}$, Lee Smith ${ }^{2}\left(\mathbb{0}\right.$, Arturo Díaz Suárez ${ }^{1}$ and Guillermo Felipe López Sánchez ${ }^{1, *(1)}$ \\ 1 Faculty of Sport Sciences, University of Murcia, San Javier, 30720 Murcia, Spain; ardiaz@um.es \\ 2 Centre for Health, Performance and Wellbeing, Anglia Ruskin University, Cambridge CB1 1PT, UK; \\ Lee.Smith@anglia.ac.uk \\ * Correspondence: Sheila.sanchez1@um.es (S.S.C.); gfls@um.es (G.F.L.S.)
}

Citation: Sánchez Castillo, S.; Smith, L.; Díaz Suárez, A.; López Sánchez, G.F. Association between Physical Activity and Comorbidities in Spanish People with Asthma-COPD Overlap. Sustainability 2021, 13, 7580. https://doi.org/10.3390/su13147580

Academic Editor: José

Carmelo Adsuar Sala

Received: 7 June 2021

Accepted: 2 July 2021

Published: 7 July 2021

Publisher's Note: MDPI stays neutral with regard to jurisdictional claims in published maps and institutional affiliations.

Copyright: (c) 2021 by the authors. Licensee MDPI, Basel, Switzerland. This article is an open access article distributed under the terms and conditions of the Creative Commons Attribution (CC BY) license (https:// creativecommons.org/licenses/by/ $4.0 /)$.

\begin{abstract}
Asthma and chronic obstructive pulmonary disease (COPD) are important conditions which often coexist. Higher rates of comorbidities among people with asthma-COPD overlap (ACO) may complicate clinical management. The aim of this study was to determine the prevalence of 30 different comorbidities and to analyze associations between these comorbidities and physical activity (PA) in Spanish people with ACO. Cross-sectional data from the Spanish National Health Survey 2017 were analyzed. A total of 198 Spanish people with ACO aged 15-69 years (60.6\% women) were included in this study. PA was measured with the International Physical Activity Questionnaire (IPAQ) short form. Diagnosis of chronic conditions were self-reported. Associations between PA and comorbidities were analyzed using multivariable logistic regression models. The most prevalent comorbidities were chronic allergy (58.1\%), chronic lumbar pain (42.4\%), chronic cervical pain $(38.4 \%)$, hypertension (33.3\%) and arthrosis (31.8\%). A PA level lower than $600 \mathrm{MET} \cdot \mathrm{min} /$ week was significantly associated with urinary incontinence $(\mathrm{OR}=3.499,95 \% \mathrm{CI}=1.369-8.944)$ and osteoporosis $(\mathrm{OR}=3.056,95 \% \mathrm{CI}=1.094-8.538)$ in the final adjusted model. Therefore, the potential influence of PA on reducing the risk of these conditions among people with ACO should be considered, not only because of the health benefits, but also because PA can contribute to a more sustainable world.
\end{abstract}

Keywords: respiratory conditions; exercise; sustainability; multimorbidity

\section{Introduction}

The Forum of International Societies (FIRS) established chronic obstructive pulmonary disease (COPD) and asthma as two of the five major respiratory diseases [1]. Both conditions are important public health problems based on their high prevalence, socioeconomic burden and morbimortality [2,3]. The Global Burden of Disease (GBD) 2019 [4], revealed a global prevalence of asthma of 3.5\% (3.6\% females; $3.4 \%$ males) and $2.8 \%$ of COPD (2.8\% females; $2.8 \%$ males). Moreover, COPD was accountable for $5.8 \%$ of global deaths in 2019 and asthma $0.82 \%$ [4]. Importantly, both diseases result in a high socioeconomic burden $[5,6]$.

These respiratory conditions are characterized by airflow limitation and respiratory symptoms, but there are differences between them that need to be noted. In asthma patients, expiratory airflow limitation and symptoms such as wheeze, shortness of breath, cough and chest tightness vary over time in intensity and improve with the use of bronchodilators or even spontaneously [2]. However, COPD is characterized by persistent expiratory airflow limitation and persistent respiratory symptoms, with or without bronchodilator reversibility [3]. Onset of COPD tends to occur after 40 years and generally in those who have been exposed to noxious particles or gases, like tobacco. However, some patients have clinical features of both asthma and COPD [2]. These clinical phenotypes have been named as Asthma-COPD overlap (ACO) or asthma + COPD. Previous studies have used the term Asthma-COPD overlap Syndrome (ACOS) to describe these patients $[7,8]$, but the latest updates of GINA [2] and GOLD [3] have named these clinical phenotypes Asthma-COPD 
overlap (ACO) or asthma + COPD, since it is not a definition of a single entity but a group of phenotypes. Several studies throughout the world have estimated the prevalence of ACO, identifying large variation, which likely reflects differences in study design, definition of ACO and population characteristics between investigations [9]. Nevertheless, a recent meta-analysis, which analyzed 21 different studies since 2011, established a worldwide pooled prevalence of $\mathrm{ACO}$ of $2.0 \%$ among the general population, $26.5 \%$ among people with asthma and $29.6 \%$ among those with COPD [10].

Despite the difficulty of diagnosing ACO patients, especially in smokers and older adults, previous literature suggests that patients with ACO experience higher rates of hospitalizations and use of healthcare resources [11-13], are more likely to have respiratory symptoms [11,14], have worse lung function [11], have poor quality of life [7,15], experience frequent exacerbations [7] and have a higher rate of mortality [16], in comparison with those with asthma or COPD alone. Moreover, the presence of comorbidities is very common among patients with ACO [17-20]. The most frequent comorbid conditions found among ACO patients in previous investigations were diabetes, cardiovascular disease, hypertension, eczema, rhinitis, musculoskeletal diseases, dyspepsia, arrhythmia, gastric ulcers, anxiety and depression [17-19].

Large investigations have demonstrated the beneficial effects of regular and sustained participation in PA in both primary and secondary prevention of several chronic diseases. [21-25]. Literature about the potential health impact of PA among ACO patients is scarce. However, PA has been shown to be beneficial in asthma control $[26,27]$ and in the reduction of exacerbations, as well as in the improvement of quality of life in people with COPD [28,29]. Moreover, previous investigations that have studied the relationship between PA and comorbidities in respiratory diseases like COPD or asthma have found a higher risk of urinary incontinence, chronic constipation, cataracts, chronic anxiety and chronic lumbar pain among Spanish people with COPD who engaged in low levels of PA [30]. In turn, Spanish asthmatics who did not achieve PA recommendations showed significant associations with the presence of urinary incontinence, osteoporosis and chronic anxiety [31].

To authors' knowledge, to date there is no literature in relation to how PA levels can contribute to reduce the risk of comorbidities in adults with ACO. However, based on the background, it could be hypothesized that low levels of PA are associated with a higher risk of developing several comorbidities.

Therefore, the aim of this investigation was to identify the prevalence of 30 different comorbidities among Spanish people with ACO aged 15-69 years and to analyze the associations between PA levels and the presence of these comorbidities.

\section{Materials and Methods}

\subsection{Study Design}

This was a cross-sectional study conducted according to Strengthening the Reporting of Observational Studies in Epidemiology (STROBE) checklist [32].

\subsection{The Survey}

Data from the Spanish National Health Survey 2017 were analyzed [33]. This survey was carried out in Spain between October 2016 and October 2017. Details of survey methods have previously been published [34]. In brief, participants were selected by a three-stage sampling method. Firstly, census sections were considered, later a systematic sampling designated the family dwellings and finally an adult (aged 15 years or more) was randomly selected from each dwelling by using the random Kish method. Data was collected by using the computer-assisted personal interviewing (CAPI) method, carried out in the participant's dwellings. The present investigation was performed in compliance with the Declaration of Helsinki of the World Medial Association. Ethical approval was not required, since data from Spanish National Health Survey are public and anonymized. 
Nevertheless, the present analysis was approved by the Ethical Research Committee of the University of Murcia.

\subsection{Participants}

A total of 23089 people residing in Spain answered the survey, of which 17,777 responded to the PA questions. Finally, 198 people with ACO residing in Spain (120 women) were included in the present analyses. Inclusion criteria for this investigation were: (1) affirmative answer to the question: Have you ever been diagnosed with COPD by a physician?", (2) affirmative answer to the question: Have you ever been diagnosed with asthma by a physician?", (3) completion of the International Physical Activity Questionnaire (IPAQ). Those adults older than 69 years were excluded, since they did not complete the IPAQ. The IPAQ was firstly designed for supervising PA in people aged from 15 to 69 years old [35], so until further testing and development is carried out in younger and older ages, its use is not advisable. Self-reported diagnosis of chronic conditions is widely used and accepted in epidemiological studies [36]. Specifically, self-report of asthma and COPD are valid methods [37,38] and have been frequently used in previous investigations [39-41]. All participants were informed about the confidentiality of the survey before responding to the questions.

\subsection{Physical Activity (Exposure)}

PA was measured by the IPAQ-short form [42]. Participants were asked for the days, hours and minutes a week that they engaged in vigorous and moderate PA and walking in the previous seven days. Total PA per week was measured as metabolic equivalent of task per minutes per week (MET.min/week) by the following formula: sum of walking + moderate + vigorous MET·min/week scores, established by the IPAQ guidelines [35]. Then, following these guidelines, PA was classified in two groups: (1) under $600 \mathrm{MET} \cdot \mathrm{min} /$ week and (2) at least $600 \mathrm{MET} \cdot \mathrm{min} /$ week.

This questionnaire has previously been validated in adult populations from different countries showing acceptable validity ( $\rho=0.30,95 \%$ CI: $0.23-0.36)$ and reliability (Spearman's $\rho=0.81,95 \%$ CI: 0.79-0.82) [43]. It has been validated in Spanish adults $(\mathrm{r}=0.277$; $p<0.05)$ with a $75 \%$ sensitivity and specificity $(\mathrm{k}=0.33)$ [44].

\subsection{Comorbidities (Outcomes)}

Thirty different comorbidities were analyzed in the present study, based on the data available in the Spanish National Health Survey 2017. Participants who answered affirmatively to the question "Have you ever been diagnosed with "chronic condition?" were determined to suffer from that specific condition. The comorbidities studied were: hypertension, myocardial infarction, angina or coronary heart disease (HD), other HD, stroke, varicose veins, arthrosis, chronic lumbar pain, chronic cervical pain, osteoporosis, chronic allergy (which includes rhinitis, conjunctivitis, dermatitis, food allergy or another kind of allergy, excluding allergic asthma), liver dysfunction, stomach or duodenal ulcer, chronic constipation, hemorrhoids, urinary incontinence, kidney problems, prostate problems (only men), menopausal problems (only women), cataracts, chronic skin problems, depression, chronic anxiety, other mental problems, migraine, malignant tumors, thyroid problems, diabetes, high cholesterol and permanent injuries caused by an accident. Some of these diseases have been considered by GINA [2] and GOLD guidelines [3] as important comorbidities in asthmatics and COPD patients. Comorbidities were classified following the ICD (International Classification of Diseases) in 12 different groups: (1) cardiovascular diseases; (2) musculoskeletal disorders; (3) immunological diseases; (4) digestive problems; (5) urogenital diseases; (6) eye problems; (7) dermatological problems; (8) mental health problems; (9) neurological disorders; (10) neoplasias; (11) endocrinal and metabolic diseases; (12) permanent injuries [45]. 


\subsection{Covariates}

Selection of covariates were based on previous identification of variables related with PA in the general population [46-48]. Unfavorable consumptions habits, like tobacco and alcohol, are important barriers to a sustainable development that need to be considered. Alcohol impacts 13 of the 17 Sustainable Development Goals [49] and tobacco use impacts health, education, poverty, global hunger, economic growth, gender equality, the environment, finance and governance [50]. Covariates included in the analysis were: sex, age, marital status, education level, body mass index (BMI), smoking habits, alcohol consumption, medication intake and presence of comorbidities. Age, BMI and numbers of comorbidities were treated as continuous variables, while the remaining variables were analyzed as categorical variables. Education level was classified based on the highest level completed according to the Spanish Classification of Education (CNED) as Level A ( $\leq 1$ st period secondary), Level B (2nd period secondary and post-secondary (not tertiary)), and Level C (tertiary) [51]. Marital status was categorized as married versus not married, which included single, separated, divorced and widowed. Smoking was divided into 3 categories: never, past and current smoker. Alcohol consumption was treated as a dichotomous variable: yes or no (abstinence in the last 12 months). Selfreported weight and height were used to calculate BMI as weight in kilograms divided by height in meters squared. Obesity was only used to describe the sample and was defined as BMI $\geq 30 \mathrm{~kg} / \mathrm{m}^{2}$. Comorbidities were analyzed as a dichotomous variable: yes (for those who had at least one comorbidity) and no (for those who did not present comorbidities). Medication intake was divided in yes or no as well. Participants were considered to take medication if they had consumed in the last two weeks at least one of the following 22 medications: (1) heart medication; (2) blood pressure medication; (3) fever medication; (4) flu/cold medication (5) sedatives; (6) rheumatism medication; (7) pain medication; (8) allergy medication; (9) antibiotics; (10) diarrhea medication; (11) digestive problems medication; (12) laxatives (13) antidepressants; (14) vitamins/minerals/tonics; (15) slimming medicines; (16) diabetes medication; (17) cholesterol medication; (18) thyroid medication; (19) contraceptive pill; (20) menopausal hormones; (21) natural products (plant-based products [34]); (22) others.

\subsection{Data Analyses}

Sample characteristics were presented through descriptive statistics. Age, BMI and number of comorbidities were described as mean and standard deviation, while the categorical variables (sex, marital status, education level, smoking, alcohol, obesity, medication intake, presence of comorbidities and PA) were analyzed through frequencies and percentages. Statistical significance between groups according to PA classification was examined by chi-squared tests, for categorical variables, and $T$ tests, for continuous variables. Descriptive statistics were used to establish the prevalence of each comorbidity and group of comorbidities too.

Multivariable logistic regression analyses were used to study the associations between weekly amount of PA and the presence of each comorbidity. The analyses were carried out by three different models. Model 1 was not adjusted for any covariates; Model 2 was adjusted for age, BMI, sex, marital status, education level, smoking and alcohol consumption; Model 3 was adjusted for the same variables of model 2 and the variables presence of comorbidities and medication intake. In every model of the regression analysis, covariates were included as categorical variables, except age and BMI, which were added as continuous variables. There were missing data only on the variable BMI (3\%).

Results from the multivariable logistic regression analyses were presented as odds ratios (OR) with $95 \%$ of confidence intervals (CI).

The present analyses were performed with the Statistical Package for Social Sciences (SPSS) version 23 (International Business Machines Corporation, Armonk, NY, USA). 


\section{Results}

A total of 198 Spanish people with ACO (120 women) with a mean age of 50 (14.9) years composed the sample; $57.6 \%$ was aged 50 or over. Table 1 shows the sample characteristics according to PA level. None of the characteristics revealed significant differences between Spanish people with ACO who achieved PA recommendations (PA $\geq 600$ MET $\cdot \mathrm{min} /$ week) and those who did not. However, when considering the whole sample, the number of participants who spent at least $600 \mathrm{MET} \cdot \mathrm{min} /$ week was significantly higher $\left(\chi^{2}=15.838\right.$; $p<0.001$ ). In relation to comorbidities, a $93.9 \%$ of people with ACO suffer from them, with a huge average of 5.3 comorbidities at the same time (maximum: 18; mode: 2; median: 4). Moreover, those who do not present comorbidities revealed a higher percentage of high PA level in comparison to those who have at least one comorbidity, but these differences were not significant.

Table 1. Sample characteristics according to PA level.

\begin{tabular}{|c|c|c|c|c|c|c|c|}
\hline \multirow[b]{2}{*}{ Characteristic } & \multirow[b]{2}{*}{ Category } & \multirow[b]{2}{*}{$\mathbf{N}$} & \multicolumn{2}{|c|}{$\begin{array}{c}\text { PA }<600 \\
\text { MET } \cdot \text { Min/Week }\end{array}$} & \multicolumn{2}{|c|}{$\begin{array}{c}\text { PA } \geq 600 \\
\text { MET } \cdot \text { Min/Week }\end{array}$} & \multirow[b]{2}{*}{$p$} \\
\hline & & & $\mathbf{N}$ & $\%$ & $\mathbf{N}$ & $\%$ & \\
\hline \multirow[t]{2}{*}{ Sex } & Men & 78 & 27 & 34.6 & 51 & 65.4 & \multirow{2}{*}{0.769} \\
\hline & Women & 120 & 44 & 36.7 & 76 & 63.3 & \\
\hline \multirow[t]{2}{*}{ Marital Status } & Not Married & 98 & 37 & 37.8 & 61 & 62.2 & \multirow{2}{*}{0.582} \\
\hline & Married & 100 & 34 & 34.0 & 66 & 66.0 & \\
\hline \multirow[t]{3}{*}{ Education } & Level A & 121 & 47 & 38.8 & 74 & 61.2 & \multirow{3}{*}{0.340} \\
\hline & Level B & 32 & 12 & 37.5 & 20 & 62.5 & \\
\hline & Level C & 45 & 12 & 26.7 & 33 & 73.3 & \\
\hline \multirow[t]{3}{*}{ Obesity } & Yes & 56 & 16 & 28.6 & 40 & 71.4 & \multirow{3}{*}{0.145} \\
\hline & No & 136 & 54 & 39.7 & 82 & 60.3 & \\
\hline & Missing & 6 & & & & & \\
\hline \multirow[t]{3}{*}{ Smoking } & Current & 60 & 21 & 35.0 & 39 & 65.0 & \multirow{3}{*}{0.977} \\
\hline & Former & 59 & 21 & 35.6 & 38 & 64.4 & \\
\hline & Never & 79 & 29 & 36.7 & 50 & 63.3 & \\
\hline \multirow[t]{2}{*}{ Alcohol } & Yes & 116 & 40 & 34.5 & 76 & 65.5 & \multirow{2}{*}{0.631} \\
\hline & No & 82 & 31 & 37.8 & 51 & 62.2 & \\
\hline \multirow[t]{2}{*}{ Medication } & Yes & 179 & 65 & 36.3 & 114 & 63.7 & \multirow{2}{*}{0.682} \\
\hline & No & 19 & 6 & 31.6 & 13 & 68.4 & \\
\hline \multirow[t]{2}{*}{ Comorbidities } & Yes & 186 & 69 & 37.1 & 117 & 62.9 & \multirow{2}{*}{0.153} \\
\hline & No & 12 & 2 & 16.7 & 10 & 83.3 & \\
\hline \multirow[t]{2}{*}{ Total } & & 198 & 71 & 35.9 & 127 & 64.1 & $<0.001$ * \\
\hline & & & Av. & SD & Av. & SD & \\
\hline Age & & 198 & 51.5 & 15.1 & 49.1 & 14.8 & 0.268 \\
\hline BMI & & 192 & 26.6 & 5.7 & 27.7 & 5.1 & 0.173 \\
\hline $\begin{array}{c}\mathrm{N}^{\mathrm{o}} \\
\text { comorbidities }\end{array}$ & & 198 & 6.1 & 4.1 & 4.9 & 4.1 & 0.054 \\
\hline
\end{tabular}

N: sample size; \%: percentage. Level A: $\leq 1$ st period secondary; Level B: 2nd period secondary and post-secondary (not tertiary); Level C: tertiary; Obesity: $\geq 30 \mathrm{~kg} / \mathrm{m}^{2}$; Av.: average; SD: Standard deviation; BMI: body mass index. $p$-values are based on chi-squared tests (categorical) and $T$ test (continuous). ${ }^{*} p<0.05$.

The prevalence of the studied comorbidities and each category of disease are shown in Table 2. The most prevalent disease among Spanish population with ACO is chronic allergy (58.1\%), followed by chronic lumbar pain (42.4\%). Considering the ICD classification, more than a half of participants suffer from immunological (58.1\%) and musculoskeletal diseases $(56.6 \%)$. The least prevalent comorbidities among ACO patients are neoplasias, eye problems, permanent injuries and dermatological problems. 
Table 2. Prevalence of comorbidities in people with ACO.

\begin{tabular}{|c|c|c|c|c|}
\hline Disease Category & Comorbidities & $\mathbf{N}$ & $\%$ & Global\% \\
\hline \multirow{6}{*}{ Cardiovascular diseases } & Hypertension & 66 & 33.3 & \multirow{6}{*}{47.0} \\
\hline & Myocardial infarction & 5 & 2.5 & \\
\hline & Angina, Coronary HD & 11 & 5.6 & \\
\hline & Other HD & 17 & 8.6 & \\
\hline & Stroke & 6 & 3.0 & \\
\hline & Varicose veins (legs) & 37 & 18.7 & \\
\hline \multirow{4}{*}{ Musculoskeletal disorders } & Arthrosis & 63 & 31.8 & \multirow{4}{*}{56.6} \\
\hline & CBP cervical & 76 & 38.4 & \\
\hline & CBP lumbar & 84 & 42.4 & \\
\hline & Osteoporosis & 21 & 10.6 & \\
\hline Immunological disease & Chronic allergy & 115 & 58.1 & 58.1 \\
\hline \multirow{4}{*}{ Digestive problems } & Liver dysfunction & 5 & 2.5 & \multirow{4}{*}{25.8} \\
\hline & Stomach/duodenal ulcer & 14 & 7.1 & \\
\hline & Chronic constipation & 28 & 14.1 & \\
\hline & Haemorrhoids & 38 & 19.2 & \\
\hline \multirow{4}{*}{ Urogenital diseases } & Urinary incontinence & 29 & 14.6 & \multirow{4}{*}{28.8} \\
\hline & Kidney problems & 19 & 9.6 & \\
\hline & Prostate problems (men) & 14 & $7.1(17.9)$ & \\
\hline & Menopausal problems (women) & 16 & $8.1(13.3)$ & \\
\hline Eye problems & Cataracts & 30 & 15.2 & 15.2 \\
\hline Dermatological problems & Chronic skin problems & 34 & 17.2 & 17.2 \\
\hline \multirow{3}{*}{ Mental health problems } & Depression & 52 & 26.3 & \multirow{3}{*}{32.8} \\
\hline & Chronic anxiety & 46 & 23.2 & \\
\hline & Other mental problems & 4 & 2.0 & \\
\hline Neurological disorder & Migraine & 62 & 31.3 & 31.3 \\
\hline Neoplasias & Malignant tumors & 19 & 9.6 & 9.6 \\
\hline \multirow{3}{*}{$\begin{array}{c}\text { Endocrinal \& metabolic } \\
\text { diseases }\end{array}$} & Thyroid problems & 16 & 8.1 & \multirow{3}{*}{41.9} \\
\hline & Diabetes & 30 & 15.2 & \\
\hline & High cholesterol & 62 & 31.3 & \\
\hline \multicolumn{2}{|c|}{ Permanent injuries (accident) } & 33 & 16.7 & 16.7 \\
\hline
\end{tabular}

ACO: asthma and COPD overlap; N: sample size; \%: percentage, HD: heart disease, CBP: chronic back pain, COPD: chronic obstructive pulmonary disease.

The associations between ACO comorbidities and PA are shown in Table 3. When models were not adjusted for any covariates, those who engage in less than $600 \mathrm{MET} \cdot \mathrm{min} /$ week of PA showed higher probability of suffering from chronic lumbar pain, osteoporosis, urinary incontinence and cataracts. When models were adjusted for age, BMI, education, marital status, smoking and alcohol, results showed a greater probability of existing osteoporosis and urinary incontinence among those who do not practice at least $600 \mathrm{MET} \cdot \mathrm{min} /$ week. Considering the third model, adjusted for presence of comorbidities and medication intake, lower levels of PA were associated with higher odds of osteoporosis and urinary incontinence, showing the last one the highest risk with an odds ratio of 3.499 with a $95 \% \mathrm{CI}=1.369-8.944$. When considering those older than 50 years $(n=114)$, urinary incontinence was significant in all models, showing the highest odds in the fully adjusted model $(\mathrm{OR}=3.906 ; 95 \% \mathrm{CI}=1.234-12.360 ; p=0.02)$, while osteoporosis was significant in the first and second model (Model 1: $\mathrm{OR}=2.86695 \% \mathrm{CI}=1.017-8.074, p=0.046$; Model 2: $\mathrm{OR}=3.18795 \% \mathrm{CI}=1.033-9.826, p=0.044)$, but not in the third model $(p=0.051)$. The other conditions were not significant in those older than 50 years. 
Table 3. Association between PA (exposure) and ACO comorbidities (outcome) estimated by multivariable logistic regression.

\begin{tabular}{|c|c|c|c|c|c|c|c|c|c|}
\hline Comorbidities & $\mathrm{OR}^{1}$ & CI $95 \%{ }^{1}$ & $p^{1}$ & $\mathrm{OR}^{2}$ & CI $95 \%^{2}$ & $p^{2}$ & $\mathrm{OR}^{3}$ & CI $95 \%^{3}$ & $p^{3}$ \\
\hline Hypertension & 1.140 & $0.618-2.104$ & 0.675 & 0.978 & $0.478-2.001$ & 0.952 & 0.998 & $0.486-1.105$ & 0.996 \\
\hline Myocardial infarction & 0.439 & $0.048-4.008$ & 0.466 & 0.131 & $0.006-2.824$ & 0.194 & 0.128 & $0.005-3.083$ & 0.205 \\
\hline Angina, Coronary HD & 0.656 & $0.168-2.557$ & 0.544 & 0.473 & $0.096-2.338$ & 0.359 & 0.471 & $0.091-2.428$ & 0.368 \\
\hline Other HD & 0.973 & $0.344-2.754$ & 0.960 & 0.825 & $0.266-2.563$ & 0.740 & 0.849 & $0.273-2.643$ & 0.778 \\
\hline Stroke & 0.891 & $0.159-4.991$ & 0.896 & 0.583 & $0.081-4.176$ & 0.591 & 0.606 & $0.085-4.303$ & 0.616 \\
\hline Varicose veins (legs) & 0.962 & $0.455-2.032$ & 0.919 & 0.687 & $0.296-1.594$ & 0.382 & 0.669 & $0.288-1.551$ & 0.349 \\
\hline Arthrosis & 1.712 & $0.926-3.165$ & 0.087 & 1.350 & $0.643-2.838$ & 0.455 & 1.329 & $0.630-2.804$ & 0.455 \\
\hline CBP cervical & 1.175 & $0.648-2.130$ & 0.595 & 1.025 & $0.534-1.967$ & 0.941 & 0.968 & $0.503-1.861$ & 0.922 \\
\hline CBP lumbar & 2.028 & $1.124-3.659$ & 0.019 * & 1.753 & $0.936-3.283$ & 0.080 & 1.702 & $0.902-3.210$ & 0.101 \\
\hline Osteoporosis & 3.334 & $1.309-8.492$ & $0.012 *$ & 3.161 & $1.141-8.757$ & $0.027 *$ & 3.056 & $1.094-8.538$ & 0.033 * \\
\hline Chronic allergy & 1.071 & $0.594-1.932$ & 0.819 & 1.061 & $0.560-2.010$ & 0.855 & 0.936 & $0.471-1.859$ & 0.850 \\
\hline Liver dysfunction & 1.198 & $0.195-7.345$ & 0.845 & 0.583 & $0.074-4.604$ & 0.609 & 0.501 & $0.056-4.495$ & 0.537 \\
\hline Stomach/duodenal ulcer & 1.373 & $0.457-4.128$ & 0.572 & 0.935 & $0.281-3.115$ & 0.913 & 0.924 & $0.253-3.370$ & 0.924 \\
\hline Chronic constipation & 1.982 & $0.885-4.440$ & 0.096 & 1.678 & $0.692-4.069$ & 0.252 & 1.619 & $0.665-3.940$ & 0.289 \\
\hline Haemorrhoids & 1.054 & $0.506-2.197$ & 0.888 & 0.994 & $0.454-2.178$ & 0.988 & 0.947 & $0.428-2.092$ & 0.892 \\
\hline Urinary incontinence & 4.275 & $1.859-9.828$ & $0.001 *$ & 3.550 & $1.396-9.029$ & $0.008 *$ & 3.499 & $1.369-8.944$ & 0.009 * \\
\hline Kidney problems & 1.339 & $0.512-3.501$ & 0.551 & 1.034 & $0.361-2.964$ & 0.950 & 1.004 & $0.346-2.912$ & 0.994 \\
\hline Prostate problems (males) & 2.200 & $0.680-7.113$ & 0.188 & 1.165 & $0.267-5.082$ & 0.839 & 2.073 & $0.373-11.509$ & 0.405 \\
\hline $\begin{array}{l}\text { Menopausal problems } \\
\text { (females) }\end{array}$ & 0.758 & $0.245-2.343$ & 0.630 & 0.778 & $0.232-2.609$ & 0.685 & 0.700 & $0.209-2.345$ & 0.563 \\
\hline Cataracts & 2.348 & $1.070-5.155$ & $0.033 *$ & 2.062 & $0.682-6.236$ & 0.200 & 2.253 & $0.730-6.954$ & 0.158 \\
\hline Chronic skin problems & 1.131 & $0.528-2.424$ & 0.751 & 0.969 & $0.428-2.194$ & 0.939 & 0.901 & $0.395-2.056$ & 0.805 \\
\hline Depression & 1.164 & $0.605-2.239$ & 0.649 & 0.772 & $0.357-1.667$ & 0.510 & 0.727 & $0.336-1.572$ & 0.418 \\
\hline Chronic anxiety & 1.927 & $0.985-3.770$ & 0.055 & 1.515 & $0.699-3.283$ & 0.293 & 1.431 & $0.659-3.109$ & 0.365 \\
\hline Other mental problems & $<0.001$ & $<0.001-<0.001$ & - & $<0.001$ & $<0.001-<0.001$ & - & $<0.001$ & $<0.001-<0.001$ & - \\
\hline Migraine & 1.081 & $0.579-2.018$ & 0.806 & 0.952 & $0.468-1.867$ & 0.887 & 0.872 & $0.439-1.734$ & 0.872 \\
\hline Malignant tumors & 1.339 & $0.512-3.501$ & 0.551 & 0.883 & $0.295-2.642$ & 0.824 & 0.861 & $0.288-2.572$ & 0.789 \\
\hline Thyroid problems & 0.799 & $0.266-2.399$ & 0.689 & 1.003 & $0.320-3.143$ & 0.996 & 0.981 & $0.314-3.069$ & 0.981 \\
\hline Diabetes & 1.042 & $0.465-2.335$ & 0.920 & 0.712 & $0.279-1.813$ & 0.476 & 0.711 & $0.278-1.814$ & 0.475 \\
\hline High cholesterol & 1.081 & $0.579-2.018$ & 0.806 & 0.946 & $0.464-1.930$ & 0.878 & 0.946 & $0.462-1.936$ & 0.879 \\
\hline $\begin{array}{l}\text { Permanent injuries } \\
\text { (accident) }\end{array}$ & 1.199 & $0.556-2.584$ & 0.643 & 1.026 & $0.455-2.315$ & 0.950 & 1.033 & $0.452-2.364$ & 0.938 \\
\hline
\end{tabular}

HD: heart disease. CBP: chronic back pain. OR: odd ratio. CI: confidence interval. ${ }^{*} p<0.05$. Reference category: no disease. ${ }^{1}$ Models not adjusted. ${ }^{2}$ Models adjusted for sex, age, BMI, education level, marital status, smoking and alcohol consumption. ${ }^{3}$ Models adjusted for sex, age, BMI, education level, marital status, smoking, alcohol consumption, medication intake and presence of comorbidities.

\section{Discussion}

To the authors' knowledge, this is the first study exploring the association between PA levels and the presence of 30 different comorbidities in Spanish people with ACO. The main results showed that chronic allergy is the most prevalent comorbidity and that those who do not engage in at least $600 \mathrm{MET} \cdot \mathrm{min} /$ week of PA have higher risk of urinary incontinence and osteoporosis.

This study revealed that the vast majority of Spanish people with ACO have comorbidities, with a $93.9 \%$ suffering from at least one comorbidity. This is higher than the prevalence of comorbidities found in the Spanish population with asthma (87.3\%) [31] but similar to the prevalence found in those with COPD (94.0\%) [30]. Moreover, participants from this study have a mean of 5.3 comorbidities, which is higher than the average found in Spanish asthmatics (3.6) [31] but lower than those with COPD (6.0) [30].

Previously, a study among British people with diagnosis of both asthma and COPD found that the most common comorbid conditions were diabetes $(50.4 \%)$, cardiovascular disease $(29.9 \%)$, hypertension (26.8\%), eczema (18.9\%) and rhinitis (18.1\%) [17]. Moreover, van Boven et al. [20] found that hypertension (49\%) was the most prevalent comorbidity among ACO patients from the MAJOrca Real-world Investigation in a COPD and Asthmatic cohort (MAJORICA), followed by anxiety, diabetes, osteoporosis and allergic rhinitis. Hypertension was one of the most prevalent comorbidities in all mentioned studies, while 
the results in the other comorbidities were different among studies. This slightly differs from the present results where the most prevalent comorbidity was chronic allergy (58.1\%), followed by chronic lumbar pain $(42.4 \%)$, chronic cervical pain $(38.4 \%)$, hypertension $(33.3 \%)$ and arthrosis $(31.8 \%)$. However, it should be taken into account that allergy was not considered as a single comorbidity in previous investigations and these investigations did not include other allergy conditions relating to food, conjunctivitis, or dermatitis. Moreover, chronic back pain was not analyzed in the British and MAJORICA study.

When considering age, a previous study revealed a prevalence of ACO of $1.6 \%$ in those aged between 20 to 44 years, $2.1 \%$ in those aged between 45 to 64 years, and $4.5 \%$ in the 60 to 84 age group [52]. Similarly, the present study revealed a higher number of ACO participants among those aged 50 and over $(57.6 \%)$ in comparison to those younger $(42.4 \%)$

In relation to PA, a recent study has determined that Spanish people with ACO engaged in an average of 2038.1 MET.min/week, achieving the recommendations of at least 600 MET $\cdot \mathrm{min} /$ week established by the Centers for Disease Control and Prevention [53] and the World Health Organization [54]. However, this amount of PA was lower than the 2514 MET-min/week found in the general population aged 18-65 years from 12 different countries [43]. Regarding the association between PA levels and the presence of comorbidities among people with ACO, previous investigations are not available. Nevertheless, to contextualize the impact of PA on ACO comorbidities, it may be useful to compare it with the impact of PA on other health states. Multivariable logistic regression analyses of the present study suggest that engaging in less than $600 \mathrm{MET} \cdot \mathrm{min} /$ week was significantly associated with a $249.9 \%$ increased odds of urinary incontinence and $205.6 \%$ for osteoporosis. No significant associations were found in the remaining 28 comorbidities when models were adjusted, but when models were not adjusted, cataracts and chronic lumbar pain showed increased odds. In comparison with a similar study carried out in Spanish people with COPD aged 15-69 years [30], increased odds for urinary incontinence in those who did not achieve PA recommendations were found (OR $=2.115$ CI 95\% $=1.213-3.689)$, but with a lower probability than found in the present study $(\mathrm{OR}=3.499 \mathrm{CI} 95 \%=1.369-8.944)$. On the contrary, COPD patients showed significant associations with chronic constipation, cataracts, chronic anxiety and chronic lumbar pain. Considering another study among Spanish asthmatics aged 15-69 years [31], significant associations between reduced PA and urinary incontinence, osteoporosis and chronic anxiety were found. The associations between PA and urinary incontinence and osteoporosis concur with our results but with lower odds (osteoporosis: $\mathrm{OR}=1.90 \mathrm{CI} 95 \%=1.00-3.61$; urinary incontinence: $\mathrm{OR}=3.10 \mathrm{CI} 95 \%=1.62-5.94)$. However, chronic anxiety results differ from the present study. In relation to osteoporosis, Oh et al. [55] demonstrated that it was more prevalent in ACO patients than in asthmatics. This may be due to the fact that ACO patients have showed high levels of inflammatory markers such as neutrophil gelatinase-associated lipocalin (NGAL) [56] and interleukin-6 (IL-6) [57], which are related to osteoporosis progression. However, Oh et al. [55] did not consider PA levels in their study and the mean age of the participants was higher (63.3 years) than the present study. Therefore, future investigations are needed to clarify why the risk of urinary incontinence and osteoporosis are higher in ACO than in COPD or asthma alone when considering PA levels, and why other comorbidities are only significant in COPD (chronic constipation, cataracts, chronic anxiety and lumbar pain) or in asthmatics (chronic anxiety). A possible explanation could be that the number of participants of the present study $(n=198)$ was lower than the number of participants with COPD $(n=601)$ or asthma $(n=1014)$ in previous studies. Nevertheless, with the current available literature, it is difficult to be sure why these differences appear. Thus, randomized control trials are needed to clarify this.

When we compared the risk of comorbidities according to PA with other studies in healthy populations, ACO patients with reduced levels of PA revealed a higher risk of several comorbidities. A longitudinal study in older women showed that performing 6.2 MET.h/week or less was associated with a $4 \%$ increased risk of urinary incontinence $(\mathrm{OR}=1.04 \mathrm{CI} 95 \%=0.92-1.18)$ [58]. In relation to osteoporosis, Shetty et al. [59] reported 
a $40 \%$ lower risk of osteoporosis among active males aged above 50 and Shenoy et al. [60] found a $32 \%$ reduced osteoporosis risk with each extra 10 METs of PA in Indian women aged 41-60 years. Similarly, the present study found a higher risk of osteoporosis in those who don't achieve PA recommendations, in the whole sample and in only those aged 50 or over. Regarding cataracts, a recent study, has shown that performing fewer than $600 \mathrm{MET} \cdot \mathrm{min} /$ week of PA was associated with $32.4 \%$ increased odds of cataracts [61]. This concurs with our results, but the odds were higher in the present study (134.8\%). However, cataracts odds of the present study were only significant when models were not adjusted. Similarly, a meta-analysis found that, when cohort studies were considered, people who practiced a medium level of PA had a 10\% lower risk of CBP lumbar $(p=0.0009)$. Our results revealed increased odds too $(102.8 \%)$, but they were only significant with unadjusted models.

The main strengths of this investigation were the use of data from a large representative survey of Spanish population aged between 15 and 69 years old, and the use of a validated, reliable and internationally recognized questionnaire to assess PA. Nevertheless, some limitations should be considered. Although the IPAQ is a reference instrument to measure PA level in youth and adult populations (15-69 years old), it is self-reported, so participants could under or overestimate their PA level. Diagnosis of asthma, COPD and comorbidities were self-reported, thus potentially introducing bias. Severity of ACO and exacerbation history were not measured in the survey, so models could not be adjusted for them. Other sociodemographic variables like employment were not included as covariates either. Furthermore, the cross-sectional design did not allow to establish the direction of the associations. Consequently, future longitudinal studies are required to clarify the direction.

\section{Conclusions}

In conclusion, data from the present study suggest that comorbidities are common among Spanish people with ACO, with a prevalence of $93.9 \%$. Considering the thirty different studied comorbidities, chronic allergy was the most prevalent, followed by chronic lumbar pain, chronic cervical pain and hypertension. Analyzing associations between PA and comorbidities when models were fully adjusted, a reduced level of PA (less than $600 \mathrm{MET} \cdot \mathrm{min}$ /week) was significantly associated with higher odds of urinary incontinence and osteoporosis, suggesting that higher levels of PA could reduce the risk of both conditions in people with ACO. Moreover, with unadjusted models, cataracts and chronic lumbar pain revealed a significant association. Regarding the other studied comorbidities, no significant associations were found. Therefore, comorbidities, specifically urinary incontinence and osteoporosis, and PA levels, should be considered in the prevention and treatment of people with ACO, not only because of the health benefits, but also because PA can contribute to a more sustainable, equitable and prosperous world [62].

Author Contributions: Supervision, L.S., A.D.S. and G.F.L.S.; Writing —original draft, S.S.C.; Writingreview \& editing, S.S.C., L.S., A.D.S. and G.F.L.S. All authors have read and agreed to the published version of the manuscript.

Funding: This research was funded by the Seneca Foundation-Agency for Science and Technology of the Region of Murcia, Spain (20773/FPI/18).

Institutional Review Board Statement: Ethical approval was not required, since data from Spanish National Health Survey are public and anonymized. Nevertheless, the present analysis was approved by the Ethical Research Committee of the University of Murcia (10/04/19).

Informed Consent Statement: Informed consent was obtained from all subjects involved in the study.

Data Availability Statement: Data supporting the findings of this study are available from the corresponding authors upon reasonable request.

Conflicts of Interest: The authors declare no conflict of interest. The funders had no role in the design of the study; in the collection, analyses, or interpretation of data; in the writing of the manuscript, or in the decision to publish the results. 


\section{References}

1. Forum of International Respiratory Societies. The Global Impact of Respiratory Disease, 2nd ed.; European Respiratory Society: Sheffield, UK, 2017.

2. Global Initiative for Asthma (GINA). Global Strategy for Asthma Management and Prevention Updated 2020. 2020. Available online: www.ginasthma.org (accessed on 15 May 2021).

3. Global Initiative for Chronic Obstructive Lung Disease. Global Strategy for the Diagnosis, Management, and Prevention of Chronic Obstructive Pulmonary Disease (2021 Report). Available online: https:/ /goldcopd.org (accessed on 15 May 2021).

4. Institute for Health Metrics and Evaluation. Global Burden of Disease Results Tool. Available online: http://ghdx.healthdata. org/gbd-results-tool (accessed on 19 April 2021).

5. Gómez Sáenz, J.T.; Quintano Jiménez, J.A.; Hidalgo Requena, A.; González Béjar, M.; Gérez Callejas, M.J.; Zangróniz Uruñuela, M.R.; Moreno Vilaseca, A.; Hernández García, R. Enfermedad Pulmonar Obstructiva Crónica: Morbimortalidad e Impacto Sanitario. Semergen 2014, 40, 198-204. [CrossRef] [PubMed]

6. Puig-Junoy, J.; Pascual-Argenté, N. Costes socioeconómicos del asma en la unión europea, estados unidos y canadá: Revisión sistemática. Rev. Esp. Salud Publica 2017, 91, 1-15.

7. Alshabanat, A.; Zafari, Z.; Albanyan, O.; Dairi, M.; FitzGerald, J.M. Asthma and COPD Overlap Syndrome (ACOS): A Systematic Review and Meta Analysis. PLoS ONE 2015, 10, e0136065. [CrossRef]

8. Tommola, M.; Ilmarinen, P.; Tuomisto, L.E.; Lehtimäki, L.; Haanpää, J.; Niemelä, O.; Kankaanranta, H. Differences between Asthma-COPD Overlap Syndrome and Adult-Onset Asthma. Eur. Respir. J. 2017, 49, 1602383. [CrossRef] [PubMed]

9. Uchida, A.; Sakaue, K.; Inoue, H. Epidemiology of Asthma-Chronic Obstructive Pulmonary Disease Overlap (ACO). Allergol Int. 2018, 67, 165-171. [CrossRef] [PubMed]

10. Hosseini, M.; Almasi-Hashiani, A.; Sepidarkish, M.; Maroufizadeh, S. Global Prevalence of Asthma-COPD Overlap (ACO) in the General Population: A Systematic Review and Meta-Analysis. Respir Res. 2019, 20, 229. [CrossRef]

11. Menezes, A.M.B.; De Oca, M.M.; Pérez-Padilla, R.; Nadeau, G.; Wehrmeister, F.C.; Lopez-Varela, M.V.; Muiño, A.; Jardim, J.R.B.; Valdivia, G.; Tálamo, C. Increased Risk of Exacerbation and Hospitalization in Subjects with an Overlap Phenotype: COPD-Asthma. Chest 2014, 145, 297-304. [CrossRef] [PubMed]

12. Hardin, M.; Cho, M.; McDonald, M.L.; Beaty, T.; Ramsdell, J.; Bhatt, S.; Van Beek, E.J.R.; Make, B.J.; Crapo, J.D.; Silverman, E.K.; et al. The Clinical and Genetic Features of COPD-Asthma Overlap Syndrome. Eur. Respir. J. 2014, 44, 341-350. [CrossRef]

13. Andersén, H.; Lampela, P.; Nevanlinna, A.; Säynäjäkangas, O.; Keistinen, T. High Hospital Burden in Overlap Syndrome of Asthma and COPD. Clin. Respir. J. 2013, 7, 342-346. [CrossRef] [PubMed]

14. Miravitlles, M.; Soriano, J.B.; Ancochea, J.; Muñoz, L.; Duran-Tauleria, E.; Sánchez, G.; Sobradillo, V.; García-Río, F. Characterisation of the Overlap COPD-Asthma Phenotype. Focus on Physical Activity and Health Status. Respir. Med. 2013, 107, 1053-1060. [CrossRef]

15. Kauppi, P.; Kupiainen, H.; Lindqvist, A.; Tammilehto, L.; Kilpeläinen, M.; Kinnula, V.L.; Haahtela, T.; Laitinen, T. Overlap Syndrome of Asthma and COPD Predicts Low Quality of Life. J. Asthma 2011, 48, 279-285. [CrossRef]

16. Kendzerska, T.; Sadatsafavi, M.; Aaron, S.D.; To, T.M.; Lougheed, M.D.; FitzGerald, J.M.; Gershon, A.S. Concurrent PhysicianDiagnosed Asthma and Chronic Obstructive Pulmonary Disease: A Population Study of Prevalence, Incidence and Mortality. PLoS ONE 2017, 12, e0173830. [CrossRef]

17. Krishnan, J.A.; Nibber, A.; Chisholm, A.; Price, D.; Bateman, E.D.; Bjermer, L.; Van Boven, J.F.M.; Brusselle, G.; Costello, R.W.; Dandurand, R.J.; et al. Prevalence and Characteristics of Asthma-Chronic Obstructive Pulmonary Disease Overlap in Routine Primary Care Practices. Ann. Am. Thorac. Soc. 2019, 16, 1143-1150. [CrossRef] [PubMed]

18. Barrecheguren, M.; Pinto, L.; Mostafavi-Pour-Manshadi, S.M.Y.; Tan, W.C.; Li, P.Z.; Aaron, S.D.; Benedetti, A.; Chapman, K.R.; Walker, B.; Fitzgerald, J.M.; et al. Identification and Definition of Asthma-COPD Overlap: The CanCOLD Study. Respirology 2020, 25, 836-849. [CrossRef]

19. Rubio, M.C.; Casamor, R.; Miravitlles, M. Identification and Distribution of COPD Phenotypes in Clinical Practice According to Spanish COPD Guidelines: The FENEPOC Study. Int. J. COPD 2017, 12, 2373-2383. [CrossRef] [PubMed]

20. van Boven, J.F.M.; Román-Rodríguez, M.; Palmer, J.F.; Toledo-Pons, N.; Cosío, B.G.; Soriano, J.B. Comorbidome, Pattern, and Impact of Asthma-COPD Overlap Syndrome in Real Life. Chest 2016, 149, 1011-1020. [CrossRef] [PubMed]

21. Haskell, W.L.; Lee, I.-M.; Pate, R.R.; Powell, K.E.; Blair, S.N.; Franklin, B.A.; Macera, C.A.; Heath, G.W.; Thompson, P.D.; Bauman, A. Physical Activity and Public Health: Updated Recommendation for Adults From the American College of Sports Medicine and the American Heart Association. Circulation 2007, 116, 1081-1093. [CrossRef] [PubMed]

22. Warburton, D.E.R.; Nicol, C.W.; Bredin, S.S.D. Health Benefits of Physical Activity: The Evidence. CMAJ 2006, 174, 801-809. [CrossRef]

23. Marques, A.; Peralta, M.; Sarmento, H.; Martins, J.; Gonzalez-Valeiro, M. Associations between Vigorous Physical Activity and Chronic Diseases in Older Adults: A Study in 13 European Countries. Eur. J. Public Health 2018, 28, 950-955. [CrossRef] [PubMed]

24. Barker, J.; Byrne, K.S.; Doherty, A.; Foster, C.; Rahimi, K.; Ramakrishnan, R.; Woodward, M.; Dwyer, T. Physical Activity of UK Adults with Chronic Disease: Cross-Sectional Analysis of Accelerometer-Measured Physical Activity in 96706 UK Biobank Participants. Int. J. Epidemiol. 2019, 48, 1167-1174. [CrossRef] 
25. Kim, S.Y.; Jeon, S.W.; Lee, M.Y.; Shin, D.W.; Lim, W.J.; Shin, Y.C.; Oh, K.S. The Association between Physical Activity and Anxiety Symptoms for General Adult Populations: An Analysis of the Dose-Response Relationship. Psychiatry Investig. 2020, 17, 29-36. [CrossRef] [PubMed]

26. Sobradillo, V.; Miravitlles, M.; Jiménez, C.A.; Gabriel, R.; Viejo, J.L.; Masa, J.F.; Fernández-Fau, L.; Villasante, C. Estudio IBERPOC En España: Prevalencia de Síntomas Respiratorios Habituales y de Limitación Crónica Al Flujo Aéreo. Arch. Bronconeumol. 2015, 35, 159-166. [CrossRef]

27. Dogra, S.; Kuk, J.L.; Baker, J.; Jamnik, V. Exercise Is Associated with Improved Asthma Control in Adults. Eur. Respir. J. 2011, 37, 318-323. [CrossRef] [PubMed]

28. Cebollero, P.; Antón, M.; Hernández, M.; Hueto, J. Walking Program for Copd Patients: Clinical Impact After Two Years of Follow-Up. Arch. Bronconeumol. 2018, 54, 439-440. [CrossRef] [PubMed]

29. Garcia-Aymerich, J.; Farrero, E.; Félez, M.A.; Izquierdo, J.; Marrades, R.M.; Antó, J.M. Risk Factors of Readmission to Hospital for a COPD Exacerbation: A Prospective Study. Thorax. 2003, 58, 100-105. [CrossRef] [PubMed]

30. Sánchez-Castillo, S.; Smith, L.; Díaz-Suárez, A.; López-Sánchez, G.F. Associations between Physical Activity and Comorbidities in People with COPD Residing in Spain: A Cross-Sectional Analysis. Int. J. Environ. Res. Public Health 2020, 17, 594. [CrossRef] [PubMed]

31. Sánchez-Castillo, S.; Smith, L.; Díaz-Suárez, A.; López-Sánchez, G.F. Analysis of Physical Activity and Comorbidities in Spanish Asthmatics. Sustainablity 2020, 12, 5256. [CrossRef]

32. STROBE Group. STROBE Statement: Checklist of Items That Should Be Included in Reports of Cross-Sectional Studies. Available online: https: / /www.strobe-statement.org/ (accessed on 28 April 2021).

33. Instituto Nacional de Estadística. Encuesta Nacional de Salud. Resultados. Available online: https://www.ine.es (accessed on 2 February 2021).

34. Ministerio de Sanidad Servicios Sociales e Igualdad; Instituto Nacional de Estadística. Encuesta Nacional de Salud 2017 Metodología; INE: Madrid, Spain, 2017.

35. IPAQ Group. Guidelines for Data Processing and Analysis of the International Physical Activity Questionnaire (IPAQ); IPAQ Group: Pescara, Italy, 2005.

36. Martin, L.M.; Leff, M.; Calonge, N.; Garrett, C.; Nelson, D.E. Validation of Self-Reported Chronic Conditions and Health Services in a Managed Care Population. Am. J. Prev. Med. 2000, 18, 215-218. [CrossRef]

37. Toren, K.; Brisman, J.; Jarvholm, B. Asthma and Asthma-like Symptoms in Adults Assessed by Questionnaires: A Literature Review. Chest 1993, 104, 600-608. [CrossRef] [PubMed]

38. Barr, R.G. Validation of Self-Reported Chronic Obstructive Pulmonary Disease in a Cohort Study of Nurses. Am. J. Epidemiol. 2002, 155, 965-971. [CrossRef] [PubMed]

39. Sánchez-Castillo, S.; Smith, L.; Díaz-Suárez, A.; López-Sánchez, G.F. Physical Activity Behaviour in People with COPD Residing in Spain: A Cross-Sectional Analysis. Lung 2019, 197, 769-775. [CrossRef] [PubMed]

40. Sánchez-Castillo, S.; Smith, L.; Díaz-Suárez, A.D.; López-Sánchez, G.F. Levels of Physical Activity in Spanish Asthmatics: A Cross-Sectional Study. Medicina 2020, 56, 643. [CrossRef]

41. Jacob, L.; López-Sánchez, G.F.; Oh, H.; Shin, J., II; Grabovac, I.; Soysal, P.; Ilie, P.C.; Veronese, N.; Koyanagi, A.; Smith, L. Association of Multimorbidity with Higher Levels of Urinary Incontinence: A Cross-Sectional Study of 23,089 Individuals Aged $\geq 15$ Years Residing in Spain. Br. J. Gen. Pract. 2021, 71, E71-E77. [CrossRef] [PubMed]

42. IPAQ Group. International Physical Activity Questionnaire. Available online: https://sites.google.com/site/theipaq/ (accessed on 11 January 2021).

43. Craig, C.L.; Marshall, A.L.; Sjöström, M.; Bauman, A.E.; Booth, M.L.; Ainsworth, B.E.; Pratt, M.; Ekelund, U.; Yngve, A.; Sallis, J.F.; et al. International Physical Activity Questionnaire: 12-Country Reliability and Validity. Med. Sci. Sport. Exerc 2003, 35, 1381-1395. [CrossRef] [PubMed]

44. Roman-Viñas, B.; Serra-Majem, L.; Hagströmer, M.; Ribas-Barba, L.; Sjöström, M.; Segura-Cardona, R. International Physical Activity Questionnaire: Reliability and Validity in a Spanish Population. Eur. J. Sport Sci. 2010, 10, 297-304. [CrossRef]

45. ICD-11-Mortality and Morbidity Statistics. Available online: https://icd.who.int/browse11/ (accessed on 8 May 2021).

46. Good, J.; Jagroop, D.; Dogra, S. Sociodemographic, Health-Related and Lifestyle Correlates of Physical Activity in Adults with Current Asthma. J. Asthma 2017, 54, 69-76. [CrossRef] [PubMed]

47. Malambo, P.; Kengne, A.P.; Lambert, E.V.; De Villiers, A.; Puoane, T. Prevalence and Socio-Demographic Correlates of Physical Activity Levels among South African Adults in Cape Town and Mount Frere Communities in 2008-2009. Arch. Public Health 2016, 74. [CrossRef]

48. Salvo, D.; Torres, C.; Villa, U.; Rivera, J.A.; Sarmiento, O.L.; Reis, R.S.; Pratt, M. Accelerometer-Based Physical Activity Levels among Mexican Adults and Their Relation with Sociodemographic Characteristics and BMI: A Cross-Sectional Study. Int. J. Behav. Nutr. Phys. Act. 2015, 12. [CrossRef] [PubMed]

49. World Health Organization Regional Office for Europe. Alcohol Consumption and Sustainable Development. Factsheet-Sustainable Development Goals: Health Targets. 2020. Available online: https:/ / www.euro.who.int/en/SDG_factsheets (accessed on 30 May 2021).

50. World Health Organization Regional Office for the Eastern Mediterranean. Tobacco and Sustainable Development. Available online: http:/ / www.emro.who.int/tfi-campaigns/2017/tobacco-and-sustainable-development.html (accessed on 30 May 2021). 
51. Instituto Nacional de Estadística. Clasificación Nacional de Educación 2014 (CNED-2014). Available online: https:/ / www.ine.es / daco/daco42/clasificaciones/cned14/CNED2014_capitulo0.pdf (accessed on 2 May 2021).

52. de Marco, R.; Pesce, G.; Marcon, A.; Accordini, S.; Antonicelli, L.; Bugiani, M.; Casali, L.; Ferrari, M.; Nicolini, G.; Panico, M.G.; et al. The coexistence of asthma and chronic obstructive pulmonary disease (COPD): Prevalence and risk factors in young, middle-aged and elderly people from the general population. PLoS ONE 2013, 8, e62985. [CrossRef] [PubMed]

53. U.S. Department of Health and Human Services. Physical Activity Guidelines for Americans, 2nd ed.; U.S. Department of Health and Human Services: Washington, DC, USA, 2018.

54. Bull, F.C.; Al-Ansari, S.S.; Biddle, S.; Borodulin, K.; Buman, M.P.; Cardon, G.; Carty, C.; Chaput, J.P.; Chastin, S.; Chou, R.; et al. World Health Organization 2020 guidelines on physical activity and sedentary behaviour. Br. J. Sports Med. 2020, 54, 1451-1462. [CrossRef] [PubMed]

55. Oh, J.Y.; Lee, Y.S.; Min, K.H.; Lee, S.Y.; Shim, J.J.; Kang, K.H.; Hur, G.Y. Osteoporosis in Patients with Asthma-Chronic Obstructive Pulmonary Disease Overlap Syndrome. Tuberc. Respir. Dis. 2018, 81, 73-79. [CrossRef] [PubMed]

56. Iwamoto, H.; Gao, J.; Koskela, J.; Kinnula, V.; Kobayashi, H.; Laitinen, T.; Mazur, W.; Mazur, W.; Respir, E. Differences in Plasma and Sputum Biomarkers between COPD and COPD-Asthma Overlap. Eur. Respir. J. 2014, 43, 421-429. [CrossRef] [PubMed]

57. Fu, J.J.; McDonald, V.M.; Gibson, P.G.; Simpson, J.L. Systemic Inflammation in Older Adults with Asthma-COPD Overlap Syndrome. Allergy, Asthma Immunol. Res. 2014, 6, 316-324. [CrossRef]

58. Danforth, K.N.; Shah, A.D.; Townsend, M.K.; Lifford, K.L.; Curhan, G.C.; Resnick, N.M.; Grodstein, F. Physical Activity and Urinary Incontinence among Healthy, Older Women. Obstet. Gynecol. 2007, 109, 721-727. [CrossRef] [PubMed]

59. Shetty, S.; Kapoor, N.; Naik, D.; Asha, H.S.; Prabu, S.; Thomas, N.; Seshadri, M.S.; Paul, T.V. Osteoporosis in Healthy South Indian Males and the Influence of Life Style Factors and Vitamin D Status on Bone Mineral Density. J. Osteoporos. 2014, 2014. [CrossRef] [PubMed]

60. Shenoy, S.; Chawla, J.K.; Gupta, S.; Sandhu, J.S. Prevalence of Low Bone Health Using Quantitative Ultrasound in Indian Women Aged 41-60 Years: Its Association with Nutrition and Other Related Risk Factors. J. Women Aging 2017, 29, 334-347. [CrossRef] [PubMed]

61. López-sánchez, G.F.; Pardhan, S.; Trott, M.; Sánchez-Castillo, S.; Jackson, S.E.; Tully, M.; Gorely, T.; López-bueno, R.; Veronese, N.; Skalska, M.; et al. The Association Between Physical Activity and Cataracts Among 17, 777 People Aged 15-69 Years Residing in Spain. Ophthalmic Epidemiol. 2020, 27, 272-277. [CrossRef] [PubMed]

62. International Society for Physical Activity and Health (ISPAH). The Bangkok Declaration on Physical Activity for Global Health and Sustainable Development. Br. J. Sports Med. 2017, 51, 1389-1391. [CrossRef] 